5. Merchant RK, Schwartz DA, Helmers RA, Dayton CS, Hunninghake GW. Bronchoalveolar lavage cellularity: the distribution in normal volunteers. Am Rev Respir Dis 1992;146:448-453.

6. Hwang JH, Lyes M, Sladewski K, Enany S, McEachern E, Mathew DP, et al. Electronic cigarette inhalation alters innate immunity and airway cytokines while increasing the virulence of colonizing bacteria. $J \mathrm{Mol}$ Med (Berl) 2016;94:667-679.

7. Martin EM, Clapp PW, Rebuli ME, Pawlak EA, Glista-Baker E, Benowitz $\mathrm{NL}$, et al. E-cigarette use results in suppression of immune and inflammatory-response genes in nasal epithelial cells similar to cigarette smoke. Am J Physiol Lung Cell Mol Physiol 2016;311: L135-L144.

8. Rennard SI, Basset G, Lecossier D, O'Donnell KM, Pinkston P, Martin $\mathrm{PG}$, et al. Estimation of volume of epithelial lining fluid recovered by lavage using urea as marker of dilution. J Appl Physiol (1985) 1986;60: 532-538.

9. Venegas C, Kumar S, Franklin BS, Dierkes T, Brinkschulte R, Tejera D, et al. Microglia-derived ASC specks cross-seed amyloid- $\beta$ in Alzheimer's disease. Nature 2017;552:355-361.

10. Franklin BS, Latz E, Schmidt FI. The intra- and extracellular functions of ASC specks. Immunol Rev 2018;281:74-87.

Copyright $@ 2019$ by the American Thoracic Society

\section{Comparison of Physiological Performance of Four Adaptive Servo Ventilation Devices in Patients with Complex Sleep Apnea}

\section{To the Editor:}

Adaptive servo ventilation (ASV) increased the risk for mortality in the SERVE-HF (Treatment of Sleep-Disordered Breathing with Predominant Central Sleep Apnea by Adaptive Servo Ventilation in Patients with Heart Failure) trial, but the underlying mechanisms are unclear (1-3). Conceivably, device algorithms controlling respiratory rate and pressure support may have led to high $\dot{\mathrm{V}}_{\mathrm{E}}$ that caused hypocapnia and consequent arrhythmias $(2,4,5)$. Whether such findings are a result of a device algorithm-based effect ("device-effect") or apply to all servoalgorithm devices ("class-effect") is uncertain $(2,6)$. We compared the performance of various ASV devices on measures of respiration and electrocardiography. Some of the results of these studies have been previously reported in the form of an abstract (7).

\section{Methods}

We performed a randomized controlled crossover physiological experiment of patients with complex sleep apnea with preserved cardiac contractility (left ventricular ejection fraction $>45 \%$ by echocardiography) who were adherent to ASV therapy. Patients

Funding support was provided by Philips-Respironics, Inc. The funding institution did not have any role in the design, management, analysis, and interpretation of the data; preparation, review, or approval of the manuscript; and decision to submit the manuscript for publication. The statements in this manuscript are solely the responsibility of the authors and do not necessarily represent the views of the Patient-Centered Outcomes Research Institute (PCORI), its Board of Governors or Methodology Committee. S.P. was also supported by NIH grants (HL138377 and MD011600) and PCORI (EAIN \#3394-UoA and PPRND-1507-31666) during the writing of this manuscript.

Originally Published in Press as DOI: 10.1164/rccm.201807-1303LE on January 3, 2019 with untreated sleep disorders such as insomnia, periodic limb movement syndrome (leg movement index $>10 / \mathrm{h}$ in prior laboratory-based polysomnography [PSG]), or restless legs syndrome were excluded. Patients were randomly assigned to 4 nights of PSG while receiving the device used in the SERVE-HF trial (ResMed S7 VPAP Adapt [ResMed]; hereafter, "S7 device"), a later version of the S7 device (ResMed S9 VPAP Adapt [ResMed]; hereafter, "S9 device"), a Philips ASV device (System One; Philips-Respironics, Inc.), and a later version of Philips ASV device (Dreamstation; Philips-Respironics, Inc.). For all devices, the expiratory positive airway pressure level was set from 4 to $15 \mathrm{~cm} \mathrm{H}_{2} \mathrm{O}$; the minimum pressure support was set at the lowest level possible $\left(3 \mathrm{~cm} \mathrm{H}_{2} \mathrm{O}\right.$ for the $\mathrm{S} 7$ device and $0 \mathrm{~cm} \mathrm{H}_{2} \mathrm{O}$ for all other devices); and maximum pressure support was $15 \mathrm{~cm} \mathrm{H} \mathrm{H}_{2} \mathrm{O}$, with maximum total pressure of $25 \mathrm{~cm}$ $\mathrm{H}_{2} \mathrm{O}$ with automatic back-up rate, whereas patients used the same mask interface on all nights. Conventional PSG with two electroencephalography leads each for frontal, occipital, and temporal; right and left electro-oculography; chin electromyography; lead II electrocardiography; finger pulseoximetry; and respiratory signals derived from the device pneumotachograph output (airflow, VT, and their derivatives: instantaneous respiratory rate [respiratory rate $=1$ /total respiratory cycle time] and $\dot{V}_{\mathrm{E}}$ [product of $\mathrm{VT}_{\mathrm{T}}$ and respiratory rate]) were collected. Electrocardiography signals $(200 \mathrm{~Hz}$ sampling rate) were analyzed for heart rate and QTc interval (MATLAB software). Patients were blinded to the device, and blinded observers scored PSG, respiratory, and electrocardiographic signals (8). Statistical analysis was performed by individuals blinded to study condition through numerical coding of the device using ANOVA or generalized linear model with repeated measures with adjustment for multiple comparisons (generalized linear model with Holm-Bonferroni correction that adjusts for control of family-wise error rate; IBM SPSS v25.0; IBM Corp.).

Fourteen patients underwent PSG on 4 nights while receiving treatment from four different devices. VE was greater during treatment with the $\mathrm{S} 7$ device when compared with all other devices during wakefulness $(P<0.0001$; Figure 1$)$. The $\dot{V}$ E for the entire night when receiving therapy with the $\mathrm{S} 7$ device was greater than the $\dot{V}$ for the entire night when receiving therapy with any of the other devices $(P<0.02$; right upper panel of figure). Respiratory rate was greater with the S7 device when compared with the S9 device for the entire night $(P<0.0001$; Table 1). During wakefulness, pressure support level was greater during S7 device therapy when compared with S9 device $(P=0.002$; Table 1$)$ and tended to be greater than pressure support level administered by the $S 9$ device during sleep $(P=0.085)$. QT interval corrected for heart rate (QTc) during S7 therapy was not different than that during any of the other therapy nights $(P=0.24)$. The tendency for greater frequency of premature ventricular beats during S7 nights when compared with any other night was observed but did not reach statistical significance $(P=$ 0.20 ). There were three episodes of nonsustained ventricular tachycardia during the entire study: two episodes during the S7 nights and one during a System One night. The total apneahypopnea index and apnea index were not different across the different devices $(P>0.6)$. The central apnea index tended to be lower in the S7 and S9 devices when compared with the System One and Dreamstation devices (ANOVA; $P=0.08$ ). 


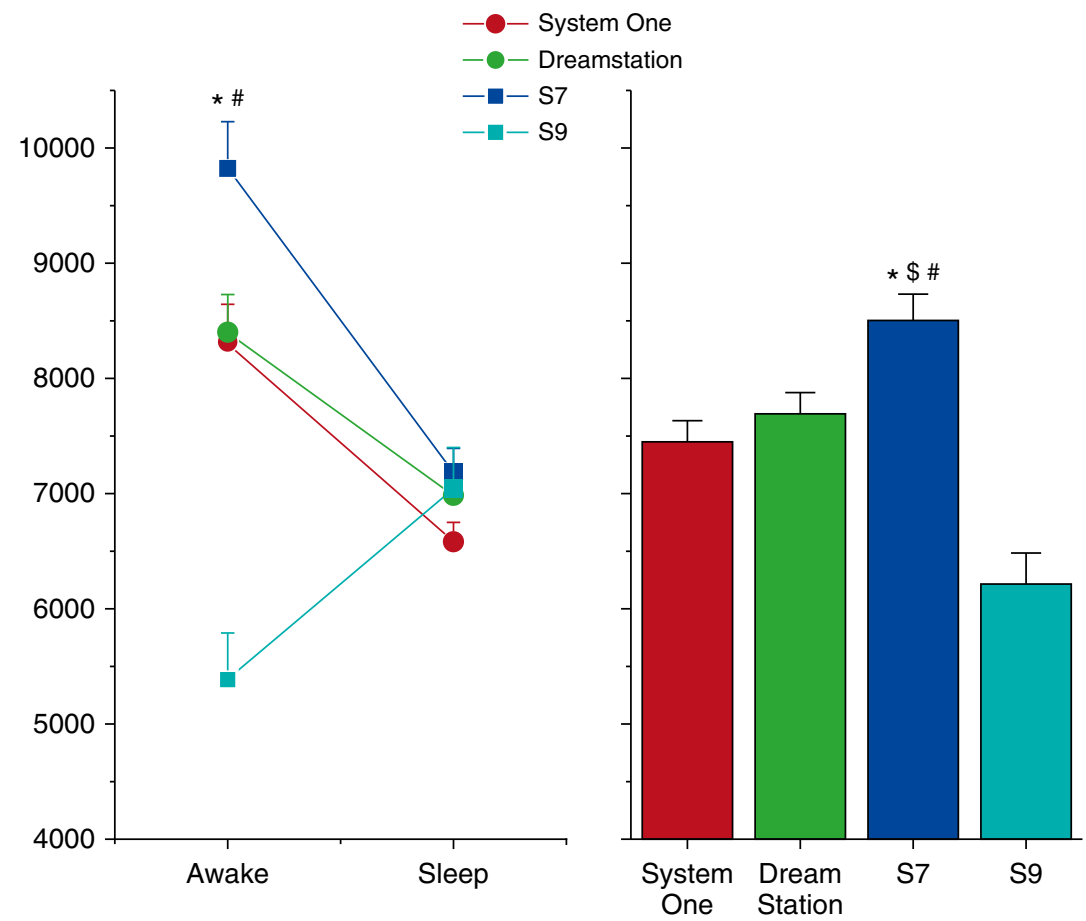

Figure 1. $\dot{V}_{E}$ by sleep-wakefulness state (left panel) and $\dot{V}_{E}$ for the entire night (right panel) are plotted for nights when undergoing laboratory-based polysomnography performed while receiving four different ASV devices: ResMed S7 VPAP Adapt (S7 device), a later version of the S7 device (ResMed S9 VPAP Adapt; S9 device), a Philips ASV device (System One), and an updated version of the Philips ASV device (Dreamstation). Mean and SE bars are plotted. Note that $\dot{V}_{E}$ for most devices was greater during wakefulness when compared with sleep. Also, the greatest $\dot{V}_{E}$ is during wakefulness while receiving therapy via the $S 7$ device. There was no order effect for randomization sequence with regard to the $\dot{V}_{E}$ findings. ${ }^{\star} P<0.05$ when compared with Dreamstation device; ${ }^{\#} P<0.05$ when compared with $S 9$ device; and ${ }^{\$} P<0.05$ when compared with System One. ASV = adaptive servo ventilation.

\section{Discussion}

There were significant differences in $\dot{V}_{E}$ delivered by various ASV devices. During wakefulness, $\dot{V}$ E was $15-40 \%$ greater during S7 night than with other devices. Moreover, the difference in $\dot{V}_{E}$ during wakefulness versus sleep states was greater for the S7 device $(+2.64 \pm 0.46)$ than any other device (System One $[+1.73 \pm$ $0.37]$; Dreamstation $[+1.42 \pm 0.37]$; and S9 device [ $-1.6 \pm$ $0.1 \mathrm{~L} / \mathrm{min}$ ]; $P<0.0001)$. Such amplification factors of the wakefulness drive to breathe can create respiratory instability and potentiate central apneas, which, in turn, would require greater pressure support and respiratory rate by the servo mechanism and/or respiratory drive (9). Such increases in $\dot{V}_{E}$ during wakefulness cause hypocapnia (respiratory alkalosis), which, in turn, could cause hypokalemia (10). Hypokalemia resulting from nighttime intracellular shifts in potassium ions can prolong QT interval and lead to potentially life-threatening cardiac arrhythmias (10). Conceivably, nighttime alkalosis resulting from excessive ventilation may lead to daytime hypokalemia and QTc prolongation through renal loss of potassium at night, with consequent arrhythmogenic effects during the daytime. Although the observed QTc prolongation during S7 therapy was small in magnitude and not statistically significant, such effects may be magnified in patients with heart failure who develop metabolic alkalosis resulting from loop diuretics. We did not, however, measure $\mathrm{CO}_{2}$ levels or potassium levels, which is a study limitation. Future research needs to be performed with adequate sample size to distinguish such differences.

In our study, we found lower sleep efficiency (greater awake time) during $\$ 9$ therapy nights when compared with other devices, including the S7 device night (Table 1). Specifically, the proportion of wakefulness time during S7 device therapy nights was better than that during S9 device nights (generalized linear model, $P<0.0001$; HolmBonferroni correction, $P=0.0002$ ). In fact, the proportion of time during wakefulness during $\$ 9$ therapy was worse than that during any other device night. In contrast to our study finding, Teschler and colleagues (11) performed an elegant study in which improvements in central apnea index and sleep architecture (notably greater REM sleep and slow wave sleep) was observed when performing a randomized crossover trial of ASV, continuous positive airway pressure, bilevel positive airway pressure, and oxygen treatment for central sleep apnea. In our study, we compared four different types of ASV devices and noticed differences in $\dot{\mathrm{V}} \mathrm{E}$ and sleep architecture across such devices, although there were no appreciable differences in central apnea index. Interestingly, we found that the magnitude of $\dot{V}_{E}$ was inversely related to proportion of time spent awake (Pearson $\left.R^{2}=-0.93 ; P=0.031\right)$. Conceivably, hypocapnia-induced cerebral vasoconstriction and reduced arousability may have played a role in such a finding $(12,13)$.

The internal validity of the study is reflected by the expected greater $\dot{V}$ E during wakefulness than during sleep, regardless of device. Moreover, the observation that the S7 device delivers greater 
Table 1. Breath Components and Pressure Assist Levels

\begin{tabular}{|c|c|c|c|c|c|c|}
\hline Device and Sleep Stage & $V_{\mathbf{T}}(m /)$ & $\begin{array}{l}\text { Respiratory } \\
\text { Rate (bpm) }\end{array}$ & $\begin{array}{l}\text { PS Level } \\
\left(\mathrm{cm} \mathrm{H}_{2} \mathrm{O}\right)\end{array}$ & Sleep Stage (\%) & QTc Interval (ms) & CAI (Events/h) \\
\hline System One & & & & & & \\
\hline $\begin{array}{l}\text { Awake } \\
\text { Sleep }\end{array}$ & $\begin{array}{l}570 \pm 33 \\
462 \pm 17\end{array}$ & $\begin{array}{l}14.9 \pm 0.6 \\
14.7 \pm 0.3\end{array}$ & $\begin{array}{l}2.0 \pm 0.4 \\
3.7 \pm 0.2\end{array}$ & $\begin{aligned} 22.8 & \pm 4.2 \\
14.9 & \pm 1.8 \text { (N1) } \\
41.9 & \pm 3.7 \text { (N2) } \\
9.7 & \pm 1.4 \text { (REM) } \\
10.6 & \pm 2.1 \text { (SWS) }\end{aligned}$ & $\begin{array}{l}396.1 \pm 6.2 \\
397.2 \pm 5.4\end{array}$ & $6.3 \pm 2.6$ \\
\hline $\begin{array}{l}\text { Dreamstation } \\
\text { Awake } \\
\text { Sleep }\end{array}$ & $\begin{array}{l}568 \pm 33 \\
512 \pm 17\end{array}$ & $\begin{array}{l}15.3 \pm 0.6 \\
14.2 \pm 0.3\end{array}$ & $\begin{array}{r}2.3 \pm 0.4 \\
4 \pm 0.2\end{array}$ & $\begin{array}{l}29.0 \pm 4.2 \\
16.0 \pm 1.8 \text { (N1) } \\
38.8 \pm 3.7 \text { (N2) } \\
7.9 \pm 1.4 \text { (REM) } \\
8.1 \pm 2.1 \text { (SWS) }\end{array}$ & $\begin{array}{l}391.5 \pm 6.4 \\
401.5 \pm 5.4\end{array}$ & $4.2 \pm 1.3$ \\
\hline $\begin{array}{l}\text { S7 } \\
\quad \text { Awake } \\
\text { Sleep }\end{array}$ & $\begin{array}{l}624 \pm 41 \\
460 \pm 21\end{array}$ & $\begin{array}{r}15.8 \pm 0.8 \\
16 \pm 0.4\end{array}$ & $\begin{array}{l}2.6 \pm 0.5 \\
2.6 \pm 0.3\end{array}$ & $\begin{array}{r}19.2 \pm 5.2 \\
12.0 \pm 2.2 \text { (N1) } \\
45.0 \pm 4.5 \text { (N2) } \\
9.2 \pm 1.7 \text { (REM) } \\
14.6 \pm 2.6 \text { (SWS) }\end{array}$ & $\begin{array}{l}400.9 \pm 6.0 \\
403.5 \pm 5.1\end{array}$ & $2.2 \pm 1.1^{*}$ \\
\hline $\begin{array}{l}\text { S9 } \\
\text { Awake } \\
\text { Sleep }\end{array}$ & $\begin{array}{l}459 \pm 41 \\
415 \pm 24\end{array}$ & $\begin{array}{l}12.0 \pm 0.8 \\
11.1 \pm 0.7\end{array}$ & $\begin{array}{r}0.0 .1 \pm 0.5 \\
0.9 \pm 0.4\end{array}$ & $\begin{aligned} 49.8 \pm 5.2^{\dagger} \\
5.1 \pm 2.2 \text { (N1) } \\
28.5 \pm 4.5 \text { (N2) } \\
7.9 \pm 1.7 \text { (REM) } \\
8.6 \pm 2.6 \text { (SWS) }\end{aligned}$ & $\begin{array}{l}393.1 \pm 6.2 \\
395.9 \pm 5.5\end{array}$ & $2.2 \pm 1.0^{*}$ \\
\hline
\end{tabular}

Definition of abbreviations: $\mathrm{bpm}=$ breaths $/ \mathrm{min} ; \mathrm{CAl}=$ central apnea index; $\mathrm{N} 1=$ non-REM sleep, stage 1; N2 = non-REM sleep, stage 2; PS = pressure support; SWS = slow wave sleep.

Data are shown as mean \pm SE.

${ }^{\star} P=0.08$ when compared to other devices.

${ }^{\dagger} P<0.05$ when compared with other devices for wakefulness state.

ventilation is similar to that observed in the SERVE-HF trial $(1,4)$, whereby device algorithms that control rate and pressure support were compounded by a minimum default pressure support of $3 \mathrm{~cm} \mathrm{H}_{2} \mathrm{O}$ that provided high levels of $\dot{\mathrm{V}}_{\mathrm{E}}$ (external validity) (4).

In conclusion, there were significant differences in $\dot{V}_{E}$ and sleep architecture while receiving ASV therapy from various available devices, and higher $\dot{\mathrm{V}}_{\mathrm{E}}$ was associated with small but statistically nonsignificant QTc prolongation. We speculate that the mechanisms underlying the adverse effects of ASV may be secondary to excessive ventilation resulting from a device-based effect rather than a class effect.

Author disclosures are available with the text of this letter at www.atsjournals.org.

James Knitter, B.S.

Omavi F. Bailey, M.D.

Chithra Poongkunran, M.D.

Aylene Flores Martinez, B.A.

Linka Martinez, B.A.

Ume Kobayashi, B.S.

Daniel Combs, M.D.

Richard Lane, M.D., Ph.D.

University of Arizona

Tucson, Arizona

Wojciech Zareba, M.D.

University of Rochester

Rochester, New York
Sairam Parthasarathy, M.D*

University of Arizona Health Sciences Center for Sleep and Circadian Sciences

Tucson, Arizona

*Corresponding author (e-mail: spartha1@email.arizona.edu).

\section{References}

1. Cowie MR, Woehrle H, Wegscheider K, Angermann C, d'Ortho MP Erdmann E, et al. Adaptive servo-ventilation for central sleep apnea in systolic heart failure. N Engl J Med 2015;373:1095-1105.

2. Magalang UJ, Pack Al. Adaptive servo-ventilation for central sleep apnea in heart failure. N Engl J Med 2016;374:691.

3. Peker $Y$, Strollo PJ Jr. A meta-analysis of positive airway pressure treatment for cardiovascular prevention: why mix apples and pears? Evid Based Med 2017;22:218-219.

4. Yamauchi M, Combs D, Parthasarathy S. Adaptive servo-ventilation for central sleep apnea in heart failure. N Engl J Med 2016;374:689.

5. Naughton MT, Kee K. Sleep apnoea in heart failure: to treat or not to treat? Respirology 2017;22:217-229.

6. Javaheri S, Brown LK, Randerath WJ. Positive airway pressure therapy with adaptive servoventilation: part 1 . Operational algorithms. Chest 2014;146:514-523.

7. Knitter J, Patel SN, Bailey O, Poongkunran C, Flores A, Martinez L, et al. Comparison of performance of four adaptive servo ventilation devices in patients with complex sleep apnea [abstract]. Sleep 2018;41:203-204.

8. Berry RB, Budhiraja R, Gottlieb DJ, Gozal D, Iber C, Kapur VK, et al.; American Academy of Sleep Medicine; Deliberations of the Sleep Apnea Definitions Task Force of the American Academy of Sleep Medicine. Rules for scoring respiratory events in sleep: update of the 
2007 AASM manual for the scoring of sleep and associated events. $J$ Clin Sleep Med 2012;8:597-619.

9. Meza S, Mendez M, Ostrowski M, Younes M. Susceptibility to periodic breathing with assisted ventilation during sleep in normal subjects. $J$ Appl Physiol (1985) 1998;85:1929-1940.

10. Urso C, Brucculeri S, Caimi G. Acid-base and electrolyte abnormalities in heart failure: pathophysiology and implications. Heart Fail Rev 2015;20:493-503.

11. Teschler H, Döhring J, Wang YM, Berthon-Jones M. Adaptive pressure support servo-ventilation: a novel treatment for Cheyne-Stokes respiration in heart failure. Am J Respir Crit Care Med 2001;164:614-619.

12. Vinayak AG, Gehlbach B, Pohlman AS, Hall JB, Kress JP. The relationship between sedative infusion requirements and permissive hypercapnia in critically ill, mechanically ventilated patients. Crit Care Med 2006;34:1668-1673.

13. Ito H, Kanno I, Ibaraki M, Hatazawa J, Miura S. Changes in human cerebral blood flow and cerebral blood volume during hypercapnia and hypocapnia measured by positron emission tomography. $J$ Cereb Blood Flow Metab 2003;23:665-670.

Copyright (C) 2019 by the American Thoracic Society

\section{A Airway Pressure Monitoring May Improve Small Airway Flow, Hemodynamics, and Tissue Oxygenation}

\author{
To the Editor:
}

We would like to congratulate Scales and Kavanagh (1) for their insightful comments reported in the editorial accompanying the study by Grieco and colleagues (2). It is true that research on resuscitation made early gains, but recent progress has been slow because of the dispersion of researchers to aspects other than elucidating the physiology and pathophysiology of cardiac arrest and resuscitation.

Although our understanding of the interaction between chest compression and mechanical ventilation remains limited, expert opinions will probably continue to rely on flawed studies that neither report nor take into consideration, when interpreting the results, the method of postintubation ventilation (self-inflating bag or ventilator), while suggesting simultaneously that early intubation during cardiopulmonary resuscitation (CPR) does not improve, or even decreases, survival (3). Ventilation with a self-inflating bag in intubated patients usually results in excessive ventilation volume and rate, thus aggravating oxygenation and hemodynamics, and surprisingly, it continues to be a major limitation in resuscitation studies.

Cordioli and colleagues (4) demonstrated that ventilation during CPR by using currently recommended chest compression rates takes place entirely below FRC and is associated with negative intrathoracic pressures during decompression. Although the thoracic pump theory is not widely accepted among the resuscitation community, the study of Cordioli and colleagues suggests that both cardiac pump and thoracic pump have a role in forward blood flow and tissue oxygenation. In this context, the study by Grieco and colleagues (2) strengthens the evidence-based notion that the

a This article is open access and distributed under the terms of the Creative Commons Attribution Non-Commercial No Derivatives License 4.0

(http://creativecommons.org/licenses/by-nc-nd/4.0/). For commercial usage and reprints, please contact Diane Gern (dgern@thoracic.org).

Originally Published in Press as DOI: 10.1164/rccm.201811-2075LE on January 3, 2019 harmony between circulation and ventilation during CPR is critical Achieving the correct balance between too little and too much ventilation is of major importance for optimizing survival, and theoretically, there must be an intrathoracic pressure limit at which the effect of a thoracic pump should be maximal. Above this limit, intrathoracic pressure would be deleterious, and under this limit, ventilation may not provide adequate blood oxygenation because of small airway closure, increasing pulmonary vascular resistance and impairing pulmonary and systemic blood flow.

Our group has recently shown an association between mean airway pressure and outcome of CPR in mechanically ventilated patients, with a value of 42.5 mbar being associated with return of spontaneous circulation (5). In our patients, simultaneous positive pressure ventilation in time with each chest compression prevented a loss of intrathoracic pressure via the airway, and probably kept the small airways open. In this study, we found no difference in end-tidal carbon dioxide between survivors and nonsurvivors, probably because of the maintenance of flow in small airways and the improvement in minute-volume ventilation during CPR (6). Of note, the rise in intrathoracic pressure in mechanically ventilated patients undergoing CPR is transmitted equally to all intrathoracic structures and squeezes out the pulmonary vessels, which increases forward blood flow, arterial oxygen partial pressure, and aortic pressure. Moreover, as hemodynamics may be aggravated in prolonged CPR because of vascular tone deterioration, the pressing effect of positive pressure ventilation and increased intrathoracic pressure on aortic wall may increase aortic resistance and retrograde volume loading, therefore enhancing the compression-related blood flow (5).

Collectively, the study by Grieco and colleagues and our findings highlight the favorable effects of the thoracic pump and the importance of intubation and mechanical ventilation in patients with cardiac arrest, supporting our deduction that the interplay between ventilation and chest compression during CPR is a key point to optimize outcomes (6). As proper timing of compression and ventilation seems to be the key for improving the circulation, the focus of the resuscitation community must immediately return to the elucidation of the physiology and pathophysiology of cardiac arrest and resuscitation.

Author disclosures are available with the text of this letter at www.atsjournals.org.

Athanasios Chalkias, Ph.D.*
University of Thessaly

Larisa, Greece

and

Hellenic Society of Cardiopulmonary Resuscitation

Athens, Greece

Theodoros Xanthos, Ph.D.

Hellenic Society of Cardiopulmonary Resuscitation

Athens, Greece

and

European University Cyprus

Nicosia, Cyprus

*Corresponding author (e-mail: thanoschalkias@yahoo.gr). 